\title{
Mola with partial live fetus 20 weeks pregnancy case
} report

\begin{abstract}
Molar pregnancy with a live fetus after 20 weeks does not usually occur and is maternal and fetal associated with complications, preeclampsia and severe: such as intrauterine growth restriction. In the partial mole there are focal placental changes and the embryo survives rarely until the second trimester. We present a case of a partial mole coexisting with a pregnancy of 20 weeks.
\end{abstract}

Keywords: molar pregnancy, mola partial, hydropic degeneration, gravid uterus, uterine fundus, obstetrical pain, bleeding, polycystic kidney disease, encephalocele, spina bifida, microphthalmia, micrognathia
Volume 4 Issue 2 - 2020

\author{
Villarreal Peral Claudia,' Leonardo Olvera \\ Gracida, ${ }^{2}$ Oswaldo Camarillo Omar \\ Contreras $^{3}$ \\ 'Medical researcher and specialist in Gynecology and Obstetrics, \\ Universidad Nacional Autonoma de Mexico, Mexico \\ ${ }^{2}$ Medical researcher and specialist in Critical Care Medicine, \\ Universidad Nacional Autonoma de Mexico, Mexico \\ ${ }^{3}$ Specialist in Gynecology and Obstetrics, Universidad Autonoma \\ de Aguascalientes, Mexico
}

Correspondence: Claudia Villarreal Peral, Medical researcher and specialist in Gynecology and Obstetrics attached to the General Hospital of Rincon de Romos, Universidad Nacional Autonoma de Mexico, Mexico, Tel 449-890-62-38, Email clauvill2003@yahoo.com.mx

Received: January 20, 2020 | Published: March 10, 2020

\section{Introduction}

Molar pregnancy, Hydatidiform mole or vesicular mole, is the result of a genetic alteration that occurs at the time of fertilization. Is characterized according to the classical definition of Hertig, by hydropic degeneration and edema of the villous stroma, the absence of vascularization in the chorionic villi and proliferation of trophoblastic epithelium but differentiated villous structure is preserved. Is a localized disease, usually resolved with uterine evacuation and, in principle, should not be considered neither invasive nor neoplastic or maligna. ${ }^{1}$ Gestational trophoblastic disease encompasses a range of disorders both premalignant: mola partial and complete, and malignant disorders: invasive mole, choriocarcinoma and tumor placental site. Partial and complete: Classically 2 types of hydatidiform are distinguished. The complete mole is characterized by the whole placenta tissue and formed by molar originates from fertilization of an oocyte by a sperm duplicate (46XX karyotype or $46 \mathrm{XY}$ ). In the cool part of the placenta it becomes molar tissue, while the rest is able to nurture the fetus. ${ }^{2}$

In the partial mole exist focal histopathological changes; Once the embryo rarely survives until the second trimester, usually associated with dizygotic twin pregnancies and births are exceptional term. Its etiopathogenesis is considered a genetic origin, associated with a triploid karyotype, 69XXY (70\%), 69XXX (27\%) and 69XYY $(3 \%)$, being a set of chromosomes maternal and two paternal games (diandrica Triploidy) and with rare cases mola partial aneuploid (haploid or tetraploid). ${ }^{3,7}$ The partial mole has an incidence of $0.005 \%$ to $0.001 \%$ of pregnancies and the incidence of partial mole with live fetus ranges from 1 to 22,000 1 per 100,000 births. In partial mola two types of hydatidiform observed associated with an egg or a fetus: egg dispermico triploid partial mole and fetus, or gemelar true. In the first example, the fetus is malformed generally is not feasible and the risk of malignancy is weak. In the second case, chromosomally normal fetus is associated with mola, having $40 \%$ Odds of and 10 born alive $\%$ proliferation sensitive trofoblastica. ${ }^{4}$

In the partial mole, fetuses are small for gestational agea disharmonious growth, which may present defects of the central nervous system defects neural tube (encephalocele, spina bifida), holoprosencephaly, agenesis of bulbs and tracts olfactory (arrienencefalia), hypoplasia of the cerebellum, agenesis of the corpus callosum, facial abnormalities such as microphthalmia, micrognathia, flattened nasal bridge, cleft lip and palate, low-set of auruiculares pavilions, short neck; in male fetuses can be seen hypospadias, cryptorchidism and micropene; They have also been described as internal alterations intestinal atresia, diaphragmatic hernia or inguinal, bile abnormalities, congenital heart disease and polycystic kidney disease. ${ }^{5}$ The presence of partial mole with live fetus is unusual for the variety of clinical complications maternal-fetal that can arise, among others associated with trophoblast proliferation such as the development of early preeclampsia, hemorrhage of the first quarter and maternal hyperthyroidism etc. ${ }^{5,6}$ The finding of hypertensive disorder associated with early pregnancy development can lead to suspicion of hydatidiform mole. , $^{7,8}$

\section{Clinical case}

The case is presented of a female patient 15 years old, without prenatal care, primipara with 20 weeks of gestation for pregnancy amenorrhea, with labor in second stage. Go presenting severe headache and presence of tinnitus, phosphenes, type obstetrical pain, bleeding transvaginal moderate dark red. On admission an average blood pressure of $130 \mathrm{mmHg}$ is detected. Physical examination, normocefala 
without cardio alterations - lung, globose abdomen expense of gravid uterus, uterine fundus of $19 \mathrm{cms}$, fetal heart rate of 140 beats per minute, vaginal examination with presence of little bleeding not active, with dilation and effacement complete, intact membranes, tendon reflexes increased $++/+++$, without the presence of edema. We performed ultrasound finding only living product of fetometria 22 weeks, weighing 449 grams, no congenital malformations apparent. Sonographically normal placenta and cord. It atiendio delivery and non-viable, male, weighing 440 grams, of 20 weeks only, immature, live product is obtained, no congenital malformations apparent (Figure 1). Placenta and cord dropsical presence of vesicles (Figure 2). ${ }^{10,11} \mathrm{He}$ requested fraction of human chorionic gonadotropin beta immediately after birth, finding levels $32.816 \mathrm{mU} / \mathrm{mL}$; in the preeclamptic profile, lactic dehydrogenase of $1,033 \mathrm{U} / \mathrm{L}$ and proteinuria $500 \mathrm{mg} / \mathrm{dL}$ in the urinalysis, other normal preeclamptic profile, Group $\mathrm{O}$ and $\mathrm{RH}$ negative. It began handling with neuroprotection with magnesium sulfate, hydralazine antihypertensive $30 \mathrm{mg}$ orally every 8 hours. It evolved satisfactorily and was discharged by appointment for consultation aimed to monitor postpartum to detect early forms of trophoblastic disease control persistent and hypertensive disease associated with pregnancy. ${ }^{12-15}$

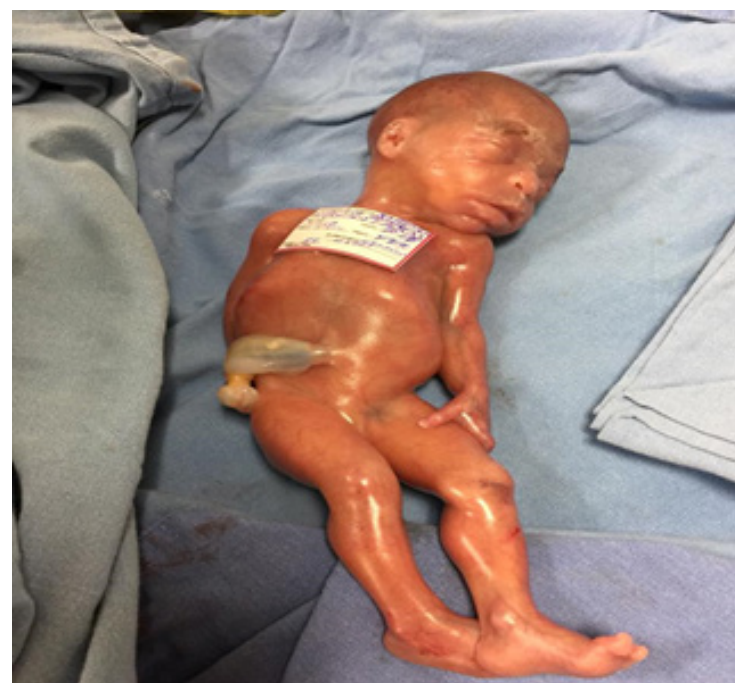

Figure I Fetus 20 weeks gestation.

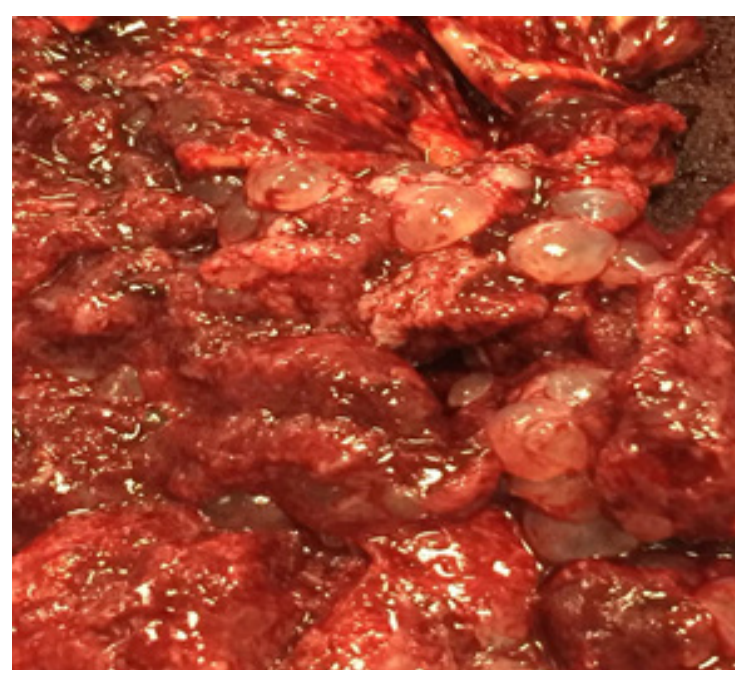

Figure 2 Placenta with hydropic presence of vesicles.

\section{Discussion}

The fetuses in partial moles, they have normal karyotypes. They represent from 0.001 to $0.01 \%$ of all pregnancies; most of them culminate in abortions in the first trimester. The clinical case is partial mole or incomplete, with live fetus of 20 weeks gestation without congenital malformations. Ultrasound has contributed to the early diagnosis of molar pregnancy. This method is more sensitive to diagnose complete molar pregnancy because it has a characteristic sonographic derived from edema and chorionic villi known as the "sign of the snowstorm." This, coupled with the presence of excessive uterine growth, characteristic of the mole, and especially high levels of hCG beta subunit, configured molar pregnancy diagnosis. In this case, were not detected by ultrasound images suggestive of cool. The diagnosis was made during the resolution of pregnancy, observing dropsical vesicles in cotyledons and umbilical cord, which was confirmed by histopathology. In addition to a hypertensive disease of pregnancy, where the natural history of the disease, led to the patient's own expected complication of mola, as it is early preeclampsia severity data. Faced with an atypical presentation of preeclampsia before the twentieth week of gestation, it is necessary to establish the differential diagnosis of preeclampsia, to give proper treatment and thus reduce maternal and fetal morbidity and mortality.

\section{Conclusion}

The molar pregnancy fetus after 20 weeks live gestation, are generally associated with severe fetal and maternal complications, such as severe preeclampsia and intrauterine growth on restriction. Embrionada resolution mola is the interruption of the pregnancy spontaneous or provoked. In cases of atypical or early preeclampsia severity data, it suggested intentionally discard the possibility of placental alteration. Treatment should be multidisciplinary in order to improve results.

\section{Acknowledgments}

None.

\section{Conflicts of interest}

The author declares there is no conflict of interest.

\section{Funding}

None.

\section{References}

1. SEGO protocols, molar pregnancy. Spain, 2004. p. 3-70.

2. Clavijo Delgado AC, Vazquez Mora Y, Pérez Buchillon R. Severe Preeclampsia and embryonic hydatiform mole with live fetus. Journal of Medical Electronics Blind Avila MediCiego. 2017;23(2).

3. Lembet A, Zorlu CG, Yalçin HR, et al. Partial diploid karyotype with live in a fetus. Int J Gynaecol Obstet. 2000;69(2):149-152.

4. Perez de Castilla J, Uzcategui Carmona M, Moreno I. Anatomopathological study of a case of partial mole. Rev Obstet Ginecol Venez. 2006;66:1-4.

5. Baergen RN. Hydatiform Moles. Manual of Pathology of the Human Placenta. $2^{\text {nd }}$ ed. Chapter 23. New York. Springer. 2011. p 427-446.

6. Garc M, Bautista E. Case Embarazoo partial molar clinic: a case report and review of the literature. Gynecol Obstet Mex. 2011;79(7):432-435. 
7. Stevens FT, Katzorke N, Tempfer C, et al. Gestational trophoblastic disorders: an update in 2015. Geburtshilfe Frauenheilkd. 2015;75(10):1043-1050.

8. Lurain JR. Gestational trophoblastic disease I: Epidemiology, pathology, clinical presentation and diagnosis of gestational trophoblastic disease, and management of hydatidi form mole. Am J Obstet Gynecol. 2010;203(6):531-539.

9. Perez de Castilla J, Uzcategui Carmona M, Moreno I. Anatomopathological study of a case of partial mole. Rev Obstet Ginecol Venez. 2006;66:1-4.

10. Wang Y, Qian H. Medical Termination of a partial hydatidiform mole and coexisting fetus during the second trimester: a case report. Oncology Letters. 2015;10(6):3525-3628.
11. Morales V, E Bautista, Vasquez S. Partial molar pregnancy: a case report and literature review. Gynecol Obstet Mex. 2011;79(7):432-435.

12. Juarez AA, PMA Durán, DLP Islands, et al. Partial mole in a live fetus: Clinical morphologic and genetic analysis. Revista Mexicana. 2009;76(5):212-214.

13. Juarez AA, DL Islands, PMA Durán. Hydatidiform mole with live fetus in the second quarter. Rev Chil Obstet Gynecol. 2010;75(2).

14. Morales García V, Bautista Gómez E, Santiago Vasquez E, et al. Partial Molar pregnancy: a case report and literature review. Gynecol Obstet Mex. 2011;79(7):432-435.

15. Seckl MJ, Sebire NJ, Berkowitz RS. Gestational trophoblastic disease. Lancet. 2010;376(9742):717-729. 